US Army Corps

of Engineers $s_{\circledast}$

Engineer Research and

Development Center

\title{
Recent Improvements to Snow Mobility Algorithms
}

Sally Shoop, Mark Bodie, Susan Frankenstein, and Matthew Bigl

August 2020 
The U.S. Army Engineer Research and Development Center (ERDC) solves the nation's toughest engineering and environmental challenges. ERDC develops innovative solutions in civil and military engineering, geospatial sciences, water resources, and environmental sciences for the Army, the Department of Defense, civilian agencies, and our nation's public good. Find out more at www.erdc.usace.army.mil.

To search for other technical reports published by ERDC, visit the ERDC online library at https://erdclibrary.on.worldcat.org/discovery. 


\section{Recent Improvements to Snow Mobility Algorithms}

Sally Shoop, Mark Bodie, Susan Frankenstein, and Matthew Bigl

Cold Regions Research Laboratory

U.S. Army Engineer Research and Development Center

72 Lyme Road

Hanover, NH 03755

Final report

Approved for public release; distribution is unlimited.

Prepared for Assistant Secretary for Army Acquisitions, Logistics \& Technology Washington, DC 20314

Under Project 471941, "Remote assessment of Snow Mechanical Properties" and "Mobility in Peat and Northern Soils" 


\section{Preface}

This study was conducted for the Assistant Secretary of the Army, Acquisition, Logistics and Technology under Project Number 471941, Task 48. The technical monitor was John Rushing.

The work was performed by the Terrestrial and Cryospheric Sciences Branch and by the Force Projection and Sustainment Branch of the Research and Engineering Division, U.S. Army Engineer Research and Development Center, Cold Regions Research and Engineering Laboratory (ERDC-CRREL).

At the time of publication, Dr. John Weatherly was Chief, Terrestrial and Cryospheric Sciences Branch; Mr. Justin Putnam was Acting Chief, Force Projection and Sustainment Branch; Mr. Jimmy Horne was Division Chief and Dr. Bert Davis, was the Technical Director for Geospatial Research and Engineering/Military Engineering. The Deputy Director of ERDCCRREL was Mr. David B. Ringelberg, and the Director was Dr. Joseph L. Corriveau.

This paper was originally published as a proceeding of the ISTVS 15th European-African Regional Conference, Prague, Czech Republic, September 9-11, 2019 and funded under the Entry and Sustainment in Complex Contested Environments Project, Mobility in Peat and Northern Soils project under the 6.2 T40 ASTMIS.

The Commander of ERDC was COL Teresa A. Schlosser and the Director was Dr. David W. Pittman. 


\title{
Recent Improvements to Snow Mobility Algorithms
}

\begin{abstract}
Northern environments cause unique terrain conditions for vehicle mobility, the most common of which are snow, ice and freezing or thawing ground. The cold regions mobility algorithms in NRMM (NATO Reference Mobility Model) were developed and implemented in the early 1990s. Meanwhile, vehicle technology has changed considerably and antilock braking, traction control, independent suspension, stability control and other drivetrain and suspension improvements are now common. Recently, we evaluated the legacy NRMM algorithms for 1) validation using modern vehicles; 2) updating sinkage algorithms for snow; 3) updating motion resistance calculations for snow; and 4) incorporating the use of chains or other traction multipliers for traction improvements on snow and ice. This paper presents recent work on validation and enhancements to the NRMM vehicle mobility model for snow and ice and the needs for future improvements.
\end{abstract}

\section{Background}

Northern environments cause unique conditions for vehicle mobility. Nearly two-thirds of the northern hemisphere is subjected to cold temperatures for prolonged periods during winter months, leaving both pavements and ground covered by snow and/or ice. Beneath the snow, the terrain can be frozen or in some combination of frost and thaw. Even the southern portion of the United States is occasionally covered by snow and ice or subjected to freeze/thaw cycles. Meanwhile, Arctic regions can be snow and ice covered for over six months.

During the late 1980s and early 1990s, CRREL developed the cold regions mobility models now currently within the NRMM (Richmond, et al., 1995). These models were based on several years of military and instrumented vehicle testing in snow covered environments (Blaisdell et al., 1990 and Richmond et al., 1990). Subsequently, military interests have shifted to desert environments and these models stagnated.

Recently, there is more interest in cold regions mobility and the models were re-evaluated for applicability using validation data from new vehicles and new vehicle technology. This paper documents the first steps at improving the calculations for snow sinkage, motion resistance, and traction. During the validation phase, the traction calculations gave reasonable estimates, but there was no method within NRMM to account for improvements due to traction aids such as chains and studs on snow and ice, so those were added. The motion resistance needed more significant improvement to better predict for a wide range of wheeled and tracked vehicles. To do this, both the snow sinkage and the motion resistance models were redone using a simple terramechanics approach (McCullough et al., 2017). More importantly, these new models relate to more readily available snow properties of depth and density. 


\section{Recent Snow Model Improvements}

\subsection{Snow Sinkage Prediction}

A conservation of mass method is used by the legacy NRMM to determine vehicle sinkage in snow (Richmond et al., 1995). This method requires only inputs of snow depth, snow density, and maximum vehicle ground contact pressure to predict sinkage into snow. The required input parameters are easily measured or estimated allowing vehicle sinkage to be predicted in various winter scenarios or snow conditions. The method equates the snow mass before and after vehicle compaction for shallow snow conditions as indicated in Fig. 1.

$$
\begin{gathered}
m=\rho_{o} A h=\rho_{f} A(h-z) \\
z=h\left[1-\frac{\rho_{o}}{\rho_{f}}\right]
\end{gathered}
$$

Where $m$ is the snow mass $(\mathrm{kg}), h$ is the initial snow depth $(\mathrm{m}), z$ is the predicted sinkage $(\mathrm{m}), \rho_{o}$ is the initial snow density $\left(\mathrm{kg} / \mathrm{m}^{3}\right), \rho_{f}$ is the final snow density $\left(\mathrm{kg} / \mathrm{m}^{3}\right)$, and $A\left(\mathrm{~m}^{2}\right)$ is the tire contact area.

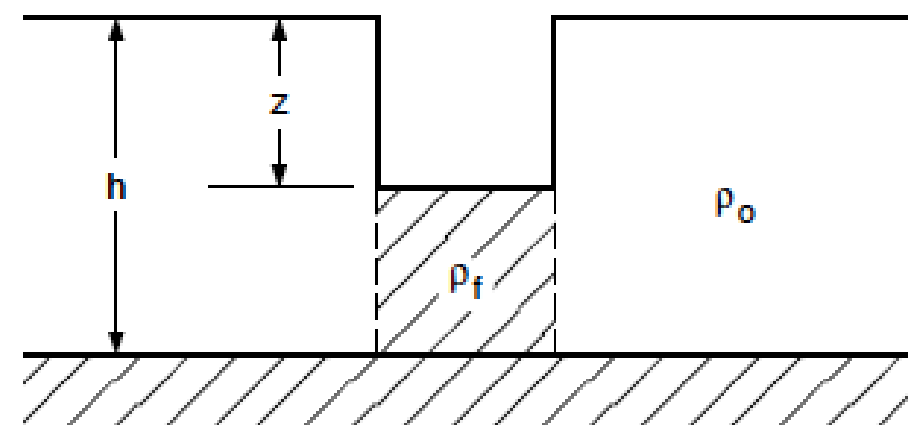

Figure 1 Vehicle sinkage for shallow snow as used in legacy NRMM (Richmond, et al., 1995).

The final snow density, $\rho_{f}$, is a function of the vehicle's maximum ground pressure, Pmax (kPa). For wheeled vehicles it is defined as

$$
\rho_{f}=\min \left(0.917,0.519+0.0023 P_{\max }\right) 1000
$$

while for tracked vehicles five categories are used to determine $\rho_{f}$ :

$$
\begin{array}{ll}
P_{\text {max }}>700 \mathrm{kPa}(101.5 \mathrm{psi}) & \rho_{f}=650 \mathrm{~kg} / \mathrm{m}^{3} \\
P_{\text {max }}>350 \mathrm{kPa}(50.8 \mathrm{psi}) & \rho_{f}=600 \mathrm{~kg} / \mathrm{m}^{3} \\
P_{\text {max }}>210 \mathrm{kPa}(30.5 \mathrm{psi}) & \rho_{f}=550 \mathrm{~kg} / \mathrm{m}^{3} \\
P_{\text {max }}<=210 \mathrm{kPa}(30.5 \mathrm{psi}) & \rho_{f}=500 \mathrm{~kg} / \mathrm{m}^{3}
\end{array}
$$

Most tracked vehicles fall into the lowest ground pressure category $(<=210 \mathrm{kPa})$ resulting in a final density of 500 $\mathrm{kg} / \mathrm{m}^{3}$. However, over-snow tracked vehicles can have ground pressures below $15 \mathrm{kPa}$ while battle tanks can have ground pressures greater than $100 \mathrm{kPa}$. Using the above final density algorithm for tracked vehicles means that all vehicles with maximum ground pressures lower than $210 \mathrm{kPa}$ have the same sinkage. 
One objective of the current work is to update the NRMM snow sinkage prediction algorithm to distinguish between tracked vehicles with differing ground pressures as is done for wheeled vehicles. Specifically, this must include the ability to predict mobility of lighter tracked vehicles traveling on deep snow, or "over snow" vehicles.

Another approach to predicting vehicle sinkage is to employ the Wong, Graber, and Preston-Thomas equation (Wong et al., 1984; and Wong and Preston-Thomas, 1987 and 1988). The equation describes the snow pressure sinkage characteristics and is given by,

$$
P_{c}=P_{w}\left[-\ln \left(1-\frac{z}{Z_{w}}\right)\right]
$$

Where $P_{c}(\mathrm{kPa})$ is the normal pressure, $z(\mathrm{~m})$ is the sinkage, and $P_{w}(\mathrm{kPa})$ and $z_{w}(\mathrm{~m})$ are regression parameters determined from experimental data obtained using a Bevameter (Bodin, 2000). Rearranging Eqn. 4 to solve for sinkage,

$$
z=z_{w}\left[1-e^{\left(-\frac{P_{c}}{P_{w}}\right)}\right]
$$

The regression parameters can be further expanded to include size effects on the pressure-sinkage curve.

$$
\begin{aligned}
& P_{w}=k_{p 1}+b k_{p 2} \\
& z_{w}=k_{z 1}+k_{z 2} / c
\end{aligned}
$$

Where $k_{p 1}, k_{p 2}, k_{z 1}$, and $k_{z 2}$ are regression constants and $c(\mathrm{~m})$ is the radius of a circular sinkage plate or the smaller side of a rectangular sinkage plate. For a wheeled vehicle $c$ is defined as the radius of the tire contact area, and for a tracked vehicle it is the width of the track. Bodin (2000) provides regression coefficients for pressure-sinkage curves for a snow depth of $70-80 \mathrm{~cm}$.

Table 1 Regression coefficients from Bodin (2000).

\begin{tabular}{|l|l|}
\hline$k_{p 1}$ & $7.35 \mathrm{kPa}$ \\
\hline$k_{p 2}$ & $141.5 \mathrm{kPa} / \mathrm{m}$ \\
\hline$k_{z 1}$ & $0.51 \mathrm{~m}$ \\
\hline$k_{z 2}$ & $0.011 \mathrm{~m}^{2}$ \\
\hline
\end{tabular}

One limitation of the Wong, Graber, and Preston-Thomas equation is that the regression coefficients must be measured using a Bevameter for each snow condition. Therefore, each snow depth and density requires bevameter data to generate the equation's regression coefficients. In the proposed approach, the benefits of both approaches are employed allowing sinkage predictions using only easy to measure or estimate snow characteristics (snow depth and density), while differentiating sinkage for track pressures below $210 \mathrm{kPa}$. By recognizing that $z_{w}$ in Eqn. 5 represents the maximum asymptotic sinkage, it is possible to employ the conservation of mass method to predict the maximum sinkage. In addition, size effects can be incorporated into the $z_{w}$ coefficient. Physically, this represents the fact that the snow deformation is not confined to simply vertical compression, but that a portion of the snow mass will be displaced laterally, and that this portion depends on how the track or wheel size interacts with the snow including edge and depth effects (Blaisdell, et al., 1990). As with the Wong equation, the size effects are inversely proportional to the width of the track or wheel. Applying the conservation of mass for the vertical and laterally displaced snow results in,

$$
\rho_{o} A h=\rho_{f} A\left(h-z_{w}\right)+\frac{b_{s}}{b} \rho_{f} A\left(h-z_{w}\right)
$$

Where $b_{s}(\mathrm{~m})$ is the size constant and $\mathrm{b}(\mathrm{m})$ is the tire or track width. The constant, $b_{s}$, and final density, $\rho_{f}$, are determined through a regression analysis, minimizing the error between the measured and predicted sinkage values. Solving Eqn. 8 for $\mathrm{Z}_{\mathrm{w}}$ results in the following, 


$$
z_{w}=h\left[1-\frac{\rho_{o}}{\rho_{f\left[1+{ }^{b_{s} / b}\right]}}\right]
$$

The maximum asymptotic sinkage, $z_{w}$, is then applied to Eqn. 5. In Eqn. $5 P_{w}$ represents snow strength, assuming a linear relationship between initial snow density and strength

$$
P_{w}=C_{r} \rho_{o}
$$

hence

$$
z=z_{w}\left[1-e^{\left(-\frac{P_{c}}{P_{w}}\right)}\right]
$$

As with the determination of $b_{s}$ and $\rho_{f}$ a regression analysis is used to determine the value of $C_{r}$ which minimizes the error between the measured and predicted sinkage values. The regression constants and the correlation to measured sinkage data is found in the Verification and Validation section.

\subsection{Motion Resistance Model}

The legacy NRMM version uses a regression equation relating motion resistance $(M R)$ to snow density, track or wheel width, and contact length to determine vehicle $M R$ in undisturbed snow. As with the NRMM sinkage equation, only easily obtained model inputs are required for the vehicle $M R$ prediction. The $M R(\mathrm{~N})$ regression equation for the first wheel $\left(M R_{l w}\right)$ or track $\left(M R_{I t}\right)$ is given by Richmond, et al. (1995) and Richmond (1993) respectively as

$$
\begin{aligned}
M R_{1 w} & =13.6041\left(\rho_{o} b a\right)^{1.26} \\
M R_{1 t} & =157.54\left(\rho_{o} b a\right)^{0.833}
\end{aligned}
$$

Where $\rho_{o}$ is the initial snow density $\left(\mathrm{kg} / \mathrm{m}^{3}\right), b$ is the track or tire width $(\mathrm{m})$, and $a$ is the length of track or tire in contact with the snow $(\mathrm{m})$. The contact length for a tire is given by

$$
a=r \arccos [(r-z) / r]
$$

Where $r$ is the tire radius (m) and $z$ is the sinkage (m). For a tracked vehicle the equation is given by

$$
a={ }^{Z} / \sin (\theta)
$$

Where $\theta$ is the angle of the leading track edge relative to the ground surface, which we assumed to be $26^{\circ}$ for all tracked vehicles.

Another method to determine a vehicle's $M R$ is to equate the work required to compress the snow with the work associated with the moving the vehicle. Assuming a constant $M R$, the work associated with moving the vehicle is given by,

$$
W_{v}=M R x
$$

where $W_{v}$ is the vehicle work, $M R$ is the motion resistance, and $x$ is the distance traveled.

The work associated with the compaction of the snow, $W_{s}$, is given by,

$$
W_{s}=\int_{0}^{z_{f}} 2 F_{c}(z) d z
$$


where $F_{c}(z)$ is the force required to compact the snow, which is a function of the compaction depth $(z)$, and $z_{f}$ is the final compaction depth. The snow compaction force can be expressed in terms of the snow stress which depends on the compaction depth and the area of the vehicle rut, or

$$
F_{c}(z)=\sigma(z) \text { Area }=\sigma(z) b x
$$

where $\sigma(z)$ is the normal stress applied to the snow during compaction, and $b$ is the rut width. Substituting Eqn. 14 into Eqn. 17 and noting that $b$ and $x$ are independent of compaction depth results in,

$$
W_{s}=2 b x \int_{0}^{z_{f}} \sigma(z) d z
$$

In equating the vehicle and snow compaction work, the distance traveled is cancelled resulting in,

$$
M R=2 b \int_{0}^{z_{f}} \sigma(z) d z
$$

If Eqn. 4 is used to define the normal stress, Eqn. 20 becomes,

$$
\begin{gathered}
M R=2 b \int_{0}^{z_{f}} P_{w}\left[-\ln \left(1-\frac{z}{z_{w}}\right)\right] d z \\
M R=2 b z_{w} P_{w}\left[\left(1-{ }^{z_{f}} / z_{w}\right) \ln \left(1-{ }^{z_{f}} / z_{w}\right)-\left(1-{ }^{z_{f}} / z_{w}\right)+1\right]
\end{gathered}
$$

The $M R$ equation is now a function of the final sinkage $\left(z_{f}\right)$, the track or tire width $(b)$, the maximum asymptotic sinkage $\left(z_{w}\right)$, and the snow strength $\left(P_{w}\right)$. If the ratio of $z_{f} / z_{w}$, becomes close to one, which occurs for most wheeled vehicles with ground pressure greater than $138 \mathrm{kPa}$, the $M R$ resistance equation (Eqn. 22) reduces to,

$$
M R=2 b z_{w} P_{w}
$$

$M R$ resistance Eqn.s 22 and 23 quantify the minimum possible snow compression work done by a vehicle, representing a perfectly efficient compaction machine. In an effort to incorporate less than ideal compaction efficiency, a regression constant, $D_{r}$, is added to Eqn. 23 and fit to measured $M R$ values,

$$
M R=2 b z_{w} P_{w} D_{r}
$$

The regression constant and the correlation to measured $M R$ data is found in the Verification and Validation section.

\subsection{Chains}

One of the primary means for improving traction on snow and ice is by adding traction aids. The ability to account for enhanced traction does not exist in the legacy NRMM. Using recent data collected from vehicle testing with chains, the impact of chains on traction coefficient values and also on the shape of the traction-slip curves was studied. A rule of thumb for the impact of chains on snow is a $30 \%$ increase in traction but modern chains were found to improve traction by up to $80 \%$ on snow and up to $90 \%$ on ice. This is a considerable improvement for vehicle mobility in winter conditions. The most significant improvements were at high slip based on the change in shape of the traction-slip curves. Without chains, traction reaches a peak and then decreases with high-slip. With chains, the traction coefficient is higher and then remains nearly constant rather than decreasing. The impact of chains on the vehicle traction versus slip curve is illustrated in Fig. 2. Antilock Braking Systems (ABS) and Traction Control Systems (TCS) are designed to limit wheel slip to the peak or maximum traction values for on-road commercial vehicles, but many military vehicles do not have these control systems and/or they are not tuned for the harsh off-road winter conditions of interest to the military. 


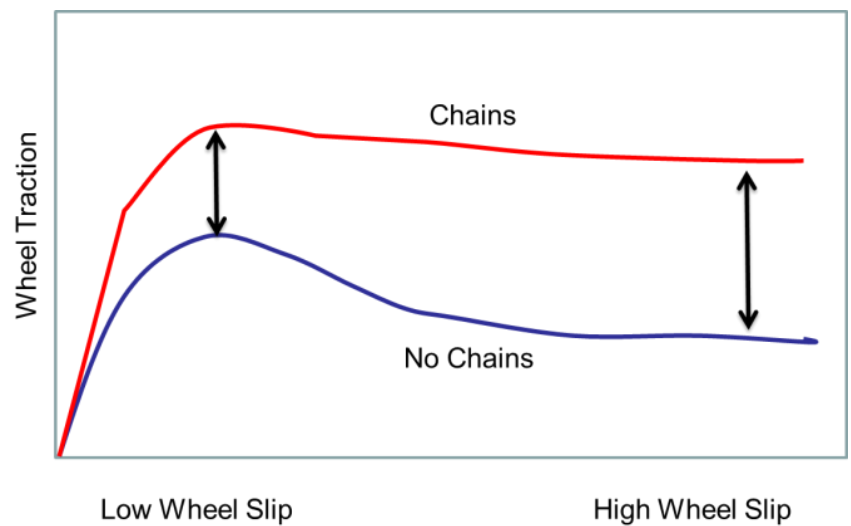

Figure 2. Idealized traction versus wheel slip curves for snow, with and without chains.

The impact of chains on vehicle traction was implemented in NRMM by applying a multiplication factor to the calculated snow traction. If the tire and chain combination and their multiplication factor is known, the factor can be included in the vehicle characteristics (vehicle file). Otherwise, the following default multiplication factors were chosen as a conservative estimate:

- 1.2 times increase in peak traction on snow

- 1.63 times increase in the traction at high slip on snow

- 1.3 times increase in peak traction on ice

- 1.25 times increase in the traction at high slip on ice (keeping in mind that high slip traction on ice is very low indeed!)

The additional motion resistance caused by the chains on packed snow or ice must also be accounted for by adding an additional resistance coefficient of 0.012 based on data measured by CRREL.

\section{Verification and Validation}

Model changes were first implemented in MATLAB and then migrated to NRMM. The new code was verified and designated as NRMM version 3.1 (not publically releasable). Validation was performed using data collected during the winter of 2018 and also using data from the literature (Richmond, et al., 1995 and Richmond, et al., 1990). In all, several wheeled and tracked vehicles were included in the validation data set as summarized below:

- Wheeled vehicles ranging from 2.4 to 36.3 metric tonnes for snow sinkage and motion resistance

- Tracked vehicles ranging from 6.6 to 57.6 metric tonnes for snow sinkage and motion resistance

- Wheeled vehicles ranging from 2.0 to 36.3 tonnes for data on chains on packed snow and ice. The results of the verification and validation study are below.

\subsection{Measured and Predicted Vehicle Snow Sinkage}

The improvements to the sinkage equation were checked against data collected from the literature and test data collected during the winter of 2018 in West Yellowstone, Montana and in Bardafoss, Norway. Measured values represent a range of undisturbed snow depths from 3.5 to $64 \mathrm{~cm}$, with sinkage values ranging from 2 to $51.5 \mathrm{~cm}$. A comparison of the legacy and the new sinkage predictions are given in Fig. 3. The updated sinkage formulation represents the measured values with a correlation coefficient $\left(\mathrm{R}^{2}\right)$ of 0.95 , and a slope of 0.996 , which is closer to a perfect fit than the legacy formation with a correlation coefficient $\left(\mathrm{R}^{2}\right)$ of 0.87 and a slope of 0.90 . A large portion of the improved fit can be attributed to the improved prediction of track vehicles. 


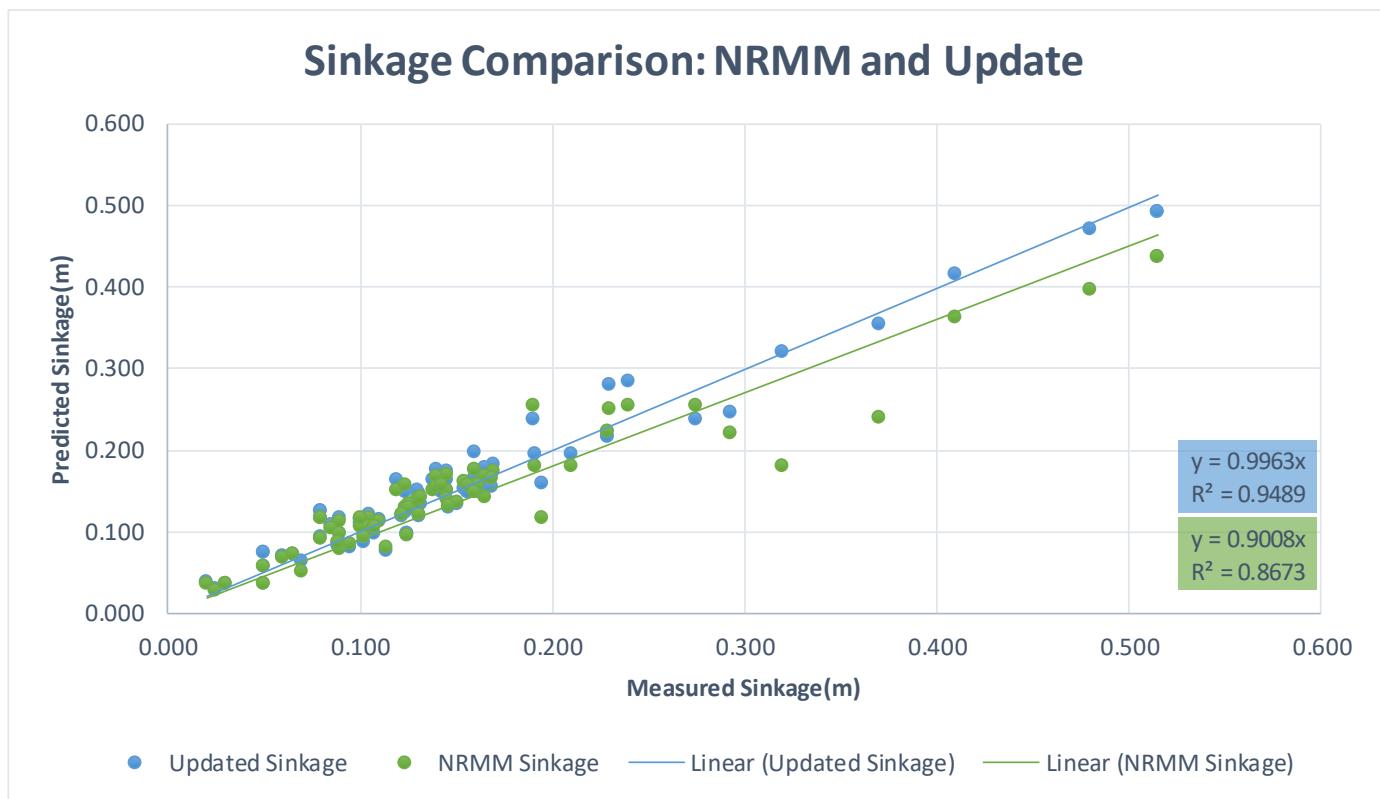

Figure 3. Legacy and updated snow sinkage predictions compared to measured data.

The regression coefficients were determined using the nonlinear least-squares freeware python script scipy.optimize.curve_fit. The coefficients from the regression analysis using Eqn.s 9 and 10 are: $b_{s}=0.614817 \mathrm{~m}, \rho_{f}=$ $0.416604 \mathrm{~g} / \mathrm{cm}^{3}$, and $C_{r}=48.36 \mathrm{kPa} / \mathrm{g} / \mathrm{cm}^{3}$. Sinkage measurements were taken with track or tire widths from 0.156 to $0.62 \mathrm{~m}$, undisturbed snow densities from 0.090 to $0.410 \mathrm{~g} / \mathrm{cm}^{3}$, undisturbed snow depths from 3.5 to $64 \mathrm{~cm}$, and ground pressures from 13.3 to $413.7 \mathrm{kPa}$. The updated sinkage equation should not be applied outside of the ranges listed above.

\subsection{Measured and Predicted Vehicle Motion Resistance}

The improvements to the $M R$ equation were checked against the data collected from the literature, Richmond (1990) and test data collected during the winter of 2018 in West Yellowstone, Montana and in Bardufoss, Norway. The data selected for the analysis were limited to fresh snow conditions with snow depths greater than $15 \mathrm{~cm}$ and below the vehicle ground clearances. The minimum snow depth requirement was selected such that other components affecting motion resistance, such as surface roughness, are negligible. The upper depth range was selected to limit confounding the $M R$ data with snow plowing effects in front of the vehicle body. Measured values represent a range of undisturbed snow depths from 15 to $55.3 \mathrm{~cm}$, with initial snow densities from 0.11 to $0.36 \mathrm{~g} / \mathrm{cm}^{3}$, tire or track width from 0.254 to $0.62 \mathrm{~m}$, and between 2 and 5 axles. The updated $M R$ equation should not be applied outside of the ranges listed above.

As with Blaisdell et al. (1995) and Richmond (1990) it was found that the number of axles was statistically significant in predicting $M R$. To account for this, Eqn. 22 was modified to include the number of axles, $N_{a}$, as well as the regression constant, $D_{r}$, such that

$$
M R=2 b z_{w} P_{w}\left[\left(1-{ }^{z_{f}} / z_{w}\right) \ln \left(1-{ }^{z_{f}} / z_{w}\right)-\left(1-{ }^{z_{f}} / z_{w}\right)+1\right] N_{a} D_{r}
$$

As with the updated sinkage equation a regression analysis was conducted using the scipy.optimize.curve_fit routine. The regression analysis resulted in a $D_{r}$ coefficient of 1.633. The updated $M R$ formulation represents the measured 
values with a correlation coefficient $\left(\mathrm{R}^{2}\right)$ of 0.55 , and a slope of 0.94 (blue data in Fig. 4), which is closer to a perfect fit than the legacy formation with a correlation coefficient $\left(\mathrm{R}^{2}\right)$ of 0.0586 and a slope of 1.25 (green data in Fig. 4).

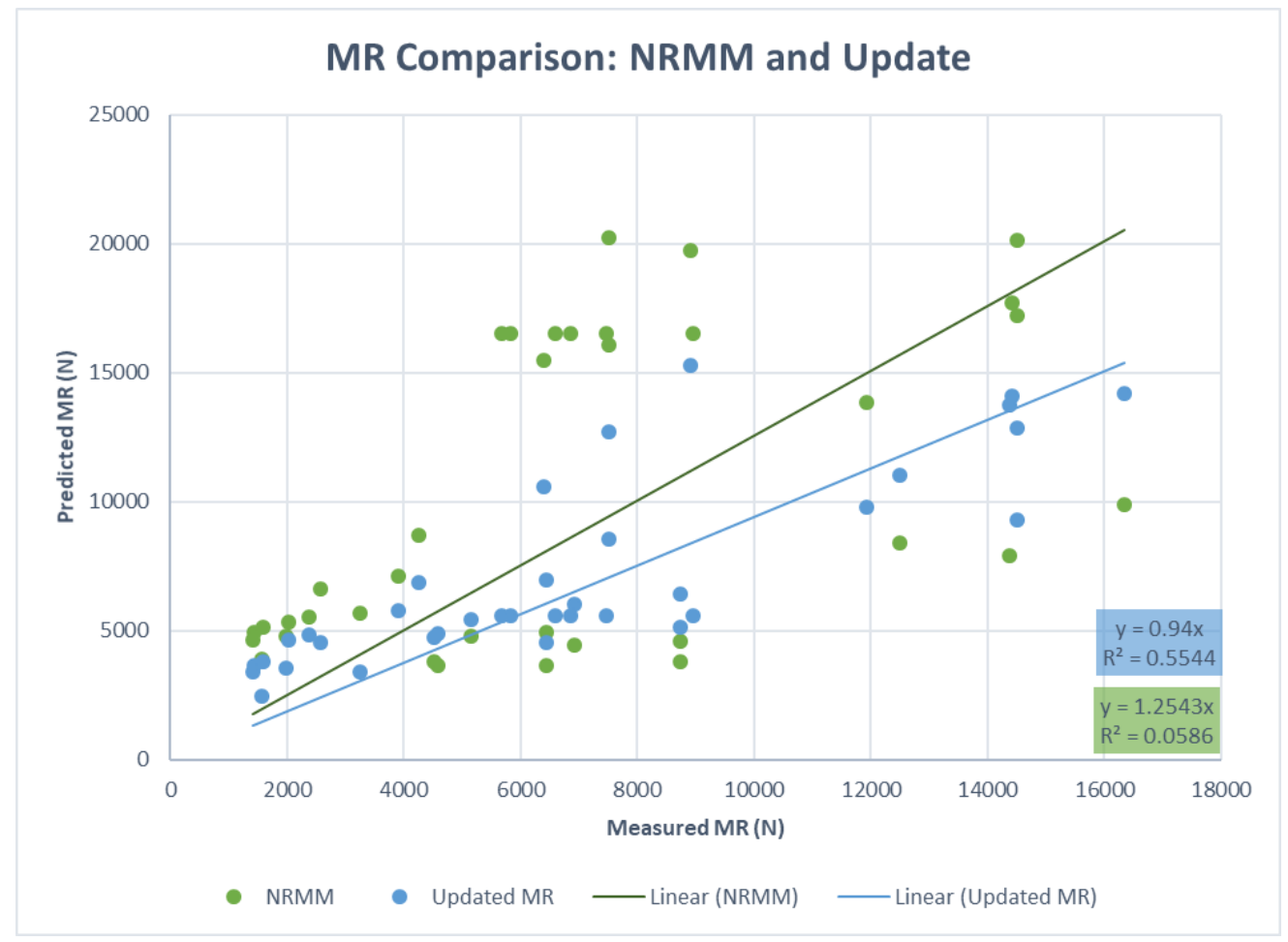

Figure 4 Legacy and updated motion resistance prediction compared to measured data.

Although the updated $M R$ equation represents an improved fit to the measured data, the fit $\left(\mathrm{R}^{2}\right)$ of 0.55 is still rather poor. In addition, the number of axles appear to have a significant effect on $M R$ which is not expected from equating snow compaction work to vehicle work. Also, the measured data from literature appears to have substantial variance. For instance, in one case where the only difference between two tests was a change in tire inflation pressure from 275 to $207 \mathrm{kPa}$ ) a corresponding $48 \%$ change in $M R$ occurred. This indicates that either there is considerable noise in the data or that a significate independent variable is missing from the prediction of $M R$. Additional work is required to fully understand vehicle $M R$ in undisturbed snow, and also to account for the additional plowing resistance when sinkage is greater than the ground clearance.

\subsection{Implementing Impact of Chains (Verification Only)}

The implementation of the chain model within NRMM is ongoing. To date, only the original test data but no validation data exists. Therefore only verification results are presented. After implementation, the NRMM traction output and speed were checked for a variety of known vehicle combinations. Once the model was determined to provide adequate traction and speed results, the speed was then mapped across a terrain to illustrate the impact of chains on vehicle speed.

The impact of using chains for snow mobility can be directly observed by the decrease in the NOGO areas of a cross country speed map as shown in Fig. 5. In mapping the speed over the test area, the NOGO area, shown in red, decreased by $98 \%$, which is considerable. While average speed for the area generally increased, it is primarily due to the reduction in the NOGO (or zero speed) areas. 

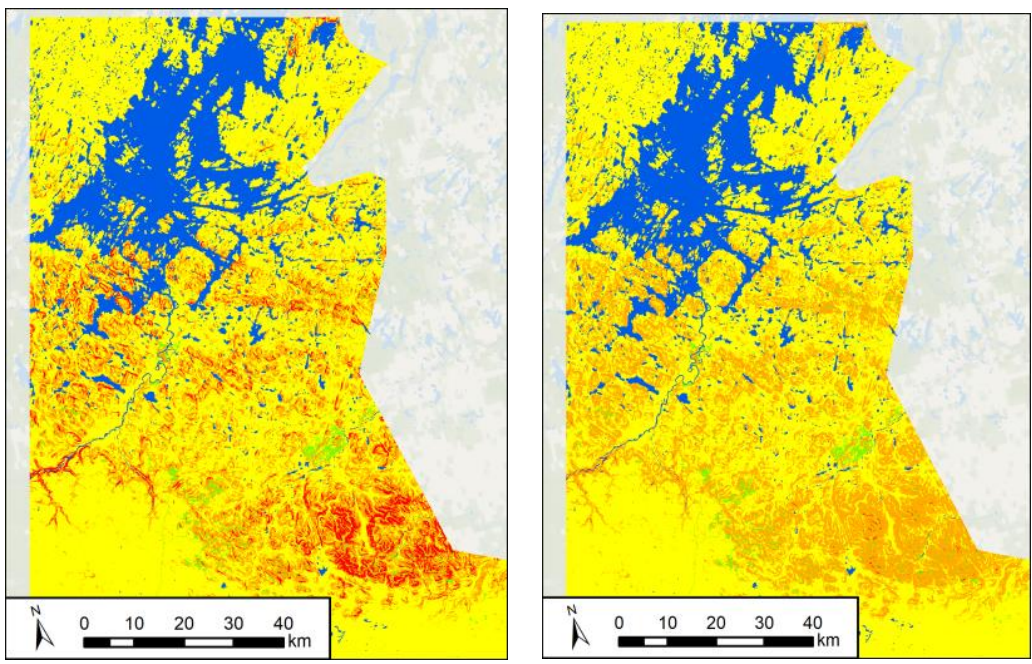

Figure 5. Comparison of speed maps for a heavy wheeled vehicle without chains (left) and with chains (right) showing reduction of NOGO areas (red) and a slight increase in overall speed (more orange and yellow).

\section{Summary and Conclusions}

Recent interest in revitalizing cold regions capabilities instigated validation data collection and improvements to snow sinkage, motion resistance, and traction aid model capabilities. This study represents the first major change in the legacy NRMM cold regions mobility model since the early 1990s. The result is improved predictions for vehicle mobility in snow, and a step in moving from purely empirical relationships to a more mechanistic model through implementation of simple terramechanics and relating that to the more basic snow properties of depth and density. Future work will expand upon this mechanistic approach using snow mechanical properties that directly influence vehicle mobility and further exploring the full range of mechanisms that impact cold regions mobility.

\section{Nomenclature}

$\begin{array}{lll}\text { a } & \text { Track contact length } & {[\mathrm{m}]} \\ \text { A } & \text { Contact area } & {\left[\mathrm{m}^{2}\right]} \\ \text { B } & \text { Rut, tire or track width } & {[\mathrm{m}]} \\ \text { c } & \text { Plate radius } & {[\mathrm{m}]} \\ \text { d } & \text { diameter } & {[\mathrm{m}]} \\ \text { D } & \text { diameter } & {[\mathrm{m}]} \\ \text { E } & \text { energy } & {[\mathrm{kJ}]} \\ \text { F } & \text { force } & {[\mathrm{N}]} \\ \text { h } & \text { snow depth } & {[\mathrm{m}]} \\ \text { m } & \text { mass } & {[\mathrm{kg}]} \\ \text { MR } & \text { Motion resistance } & {[\mathrm{N}]} \\ \text { N } & \text { Number of axles } & \\ \text { P } & \text { Pressure } & {[\mathrm{kPa}]} \\ \rho & \text { Density } & {\left[\mathrm{kg} / \mathrm{m}^{3}\right]} \\ \mathrm{r} & \text { Radius } & {[\mathrm{m}]} \\ \sigma & \text { Normal stress } & {[\mathrm{kPa}]} \\ \mathrm{V} & \text { Velocity } & {[\mathrm{m} / \mathrm{s}]} \\ \text { W } & \text { Work } & {[\mathrm{N}-\mathrm{m}]} \\ \mathrm{x} & \text { Travel distance } & {[\mathrm{m}]} \\ \mathrm{z} & \text { sinkage } & {[\mathrm{m}]}\end{array}$




\section{Acknowledgements}

This project was funded by the Entry and Sustainment in Complex, Contested Environment work package (project 468822) and the USMC maneuver study (project H6H482) and we gratefully acknowledge this support. We also appreciate the expertise provided by the US Marine Corps and the West Yellowstone staff of the Nevada Automotive Research Center.

\section{References}

Blaisdell, G.L., Richmond, P.W., Green, C.E., Shoop, S. A., and Alger, R.G., 1990. Wheels and Tracks in Snow: Validation of the CRREL Shallow Snow Mobility Model. CR 90-09. US Army Corps of Engineers, Cold Regions Research \& Engineering Laboratory, Hanover, NH.

Bodin, A., 2000. Bevameter - Development of a device to characterize the characteristics of soft terrain. Proc. of the 8th European Conf. of the Intl. Soc. for Terrain-Vehicle Sys. 1-8.

McCullough, M., J. Paramsothy, J. Preston-Thomas, H. Hodges, S. Shoop. 2017. Simple Terramechanics Models and their Demonstration in the Next Generation NATO Reference Mobility Model. 2017 NDIA Ground Vehicle Systems Engineering \& Technology Symposium, 8-10 August, Novi, MI.

Richmond, P.W., Blaisdell, G.L., Green, C.E., 1990. Wheel and tracks in snow: Second validation study of the CRREL shallow snow mobility model. CR 90-13. US Army Corps of Engineers, Cold Regions Research \& Engineering Laboratory, Hanover, NH.

Richmond, P.W., 1993. A Discussion of Deep Snow Mobility Models. NATO Reference Mobility Model (NRMM) Technical Management Committee Meeting, Trier, Germany, 12-13 May.

Richmond, P.W., Shoop, S.A., Blaisdell, G.L., 1995. Cold regions mobility models. CR 95-1. US Army Corps of Engineers, Cold Regions Research \& Engineering Laboratory, Hanover, NH.

Wong, J.Y., Garber, M., Preston-Thomas, J., 1984. Theoretical prediction and experimental substantiation of the ground pressure distribution and tractive performance of tracked vehicles. Proc. Inst. Mech. Engrs. 198 (D15): 265-285.

Wong J.Y., Preston-Thomas, J., 1987. Further developments and applications of a computer simulation model for parametric evaluation of tracked vehicle design. Proc. of the 9th Intl. Conf. ISTVS I. 200-212.

Wong, J.Y., Preston-Thomas, J., 1988. Investigation into the effects of suspension characteristics and design parameters on the performance of tracked vehicles using an advanced computer simulation model. Proc. Inst. Mech. Engrs. 202(D3), 143-161. 


\section{REPORT DOCUMENTATION PAGE}

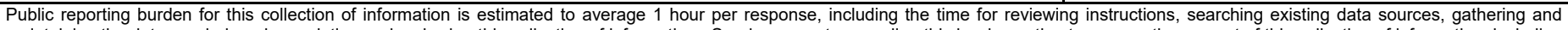

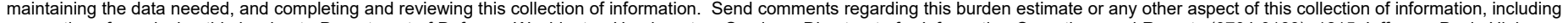

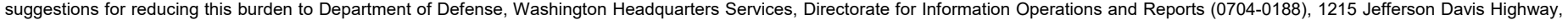

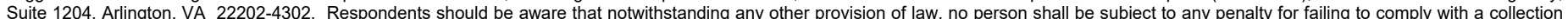
of information if it does not display a currently valid OMB control number. PLEASE DO NOT RETURN YOUR FORM TO THE ABOVE ADDRESS.

\begin{tabular}{l|l|l|l} 
1. REPORT DATE & 2. REPORT TYPE & 3. DATES COVERED (FrOm - To)
\end{tabular}

August 2020 Final

4. TITLE AND SUBTITLE

Recent Improvements to Snow Mobility Algorithms 5a. CONTRACT NUMBER

5b. GRANT NUMBER

5c. PROGRAM ELEMENT NUMBER

6. AUTHOR(S)

5d. PROJECT NUMBER

Sally Shoop, Mark Bodie, Susan Frankenstein, and Matthew Bigl

471941

5e. TASK NUMBER

48

5f. WORK UNIT NUMBER

7. PERFORMING ORGANIZATION NAME(S) AND ADDRESS(ES)

U.S. Army Engineer Research and Development Center

8. PERFORMING ORGANIZATION REPORT NUMBER

Cold Regions Research Laboratory

72 Lyme Road

ERDC/CRREL MP-20-9

Hanover, NH 03755

9. SPONSORING / MONITORING AGENCY NAME(S) AND ADDRESS(ES)

Assistant Secretary of the Army/Acquisitions, Logistics \& Technology

103 Pentagon

Washington, DC 20314-1000

10. SPONSOR/MONITOR'S ACRONYM(S)

11. SPONSOR/MONITOR'S REPORT NUMBER(S)

\section{DISTRIBUTION / AVAILABILITY STATEMENT}

Approved for public release; distribution is unlimited.

\section{SUPPLEMENTARY NOTES}

Originally published in Proceedings of the ISTVS 15th European-African Regional Conference, Prague, Czech Republic, September 9-11, 2019.

\section{ABSTRACT}

Northern environments cause unique terrain conditions for vehicle mobility, the most common of which are snow, ice and freezing or thawing ground. The cold regions mobility algorithms in NRMM (NATO Reference Mobility Model) were developed and implemented in the early 1990s. Meanwhile, vehicle technology has changed considerably and antilock braking, traction control, independent suspension, stability control and other drivetrain and suspension improvements are now common. Recently, we evaluated the legacy NRMM algorithms for 1) validation using modern vehicles; 2) updating sinkage algorithms for snow; 3) updating motion resistance calculations for snow; and 4) incorporating the use of chains or other traction multipliers for traction improvements on snow and ice. This paper presents recent work on validation and enhancements to the NRMM vehicle mobility model for snow and ice and the needs for future improvements.

\section{SUBJECT TERMS}

Snow, mobility, NRMM, Validation, Sinkage, Chains, Motion resistance

\section{SECURITY CLASSIFICATION OF:}

\begin{tabular}{l|r}
\hline a. REPORT & b. ABSTRACT \\
Unclassified & Unclassified
\end{tabular}

17. LIMITATION OF ABSTRACT

c. THIS PAGE

Unclassified

SAR

18. NUMBER
OF PAGES
13

19a. NAME OF RESPONSIBLE PERSON

19b. TELEPHONE NUMBER (include area code) 